\title{
Association between house dust mites sensitization and level of asthma control and severity in children attending Mansoura University Children's Hospital
}

\author{
Nahla Mohamed Okasha ${ }^{1}$, Amr Ali Sarhan ${ }^{2}$ and Engy Osman Ahmed ${ }^{3^{*}}$ (D)
}

\begin{abstract}
Background: House dust mites (HDM) are considered as a major source of indoor aeroallergen all over the world that precipitate allergic reactions including rhinoconjunctivitis, food allergy, atopic dermatitis, and allergic asthma. In this study, we aimed to assess the clinical and laboratory profile of some Egyptian asthmatic children who are sensitized to house dust mites and determine the association of HDM sensitization and severity of asthma according to recent GINA guidelines.

Results: The most frequent clinical phenotype among the HDM-positive group was a cough (96.7\%), while the clinical phenotypic wheeze was frequent in HDM negative group (96.7\%). There is a statistically significant difference between studied cases classified according to sensitivity to HDM regarding level of asthma control (50.0\% were uncontrolled among cases sensitive to HDM and 56.7\% of cases non-sensitive to HDM were controlled $\left(p=0.001^{*}\right)$. Severity according to treatment results was significantly higher among cases sensitive to HDM (26.7\% of cases sensitive to HDM versus 3.3\% of cases non-sensitive to HDM), $p=0.017$.
\end{abstract}

Conclusions: HDM sensitization is associated mainly with cough asthma phenotype and allergic rhinitis in our studied cases. HDM sensitization increases asthma severity and decreases the ability to control asthma symptoms.

Trial registration: ClinicalTrial.gov, NCT04958616.

Keywords: Asthma severity, Dermatophagoides farina, Dermatophagoides pteronyssinus, Spirometry

\section{Background}

Bronchial asthma is considerd as an important worldwide illness that affects different age categories. Asthma prevalence is still increasing specialy in developing countries, thus rising treatment costs leading to more economic burden for patients and health authorities [1].

Severity of bronchial asthma can be assessed evaluated retrospectively according to the step of treatment that achieve control of asthma symptoms and flare up attacks, after the patient has undergone controller drugs for at least

\footnotetext{
*Correspondence: ahmedengy1234@gmail.com

${ }^{3}$ Allergy and Pediatric Pulmonology Unit, Mansoura University Faculty of Medicine, Mansoura, Egypt

Full list of author information is available at the end of the article
}

three months [2]. Uncontrolled asthma not only increases emergency department visits and hospitalizations, but also affects activities of daily living. More than $50 \%$ of patients had restrictions in daily activities in all age groups [3].

House dust mites (HDM) are considered as a major source of indoor aeroallergen all over the world that precipitate allergic reactions including rhinoconjunctivitis, food allergy, atopic dermatitis, and allergic asthma [4].

The most prevalent HDM isolated from dust samples are Dermatophagoides pteronyssinus and Dermatophagoides farina. Allergens derived from mites can trigger allergy symptoms by either close external skin or mucous contact (conjunctivitis, eczema), respiratory system (rhinitis, asthma, and eczema), and ingestion rout 
(urticarial and anaphylaxis) in atopic persons [5]. It is clear that mite allergy is a major factor in asthma in many parts of the world, and avoiding it in the long term can be effective in preventing allergies and reducing the development and severity of respiratory diseases [6].

Hossny et al. stated that Dermatophagoides farina and Dermatophagoides pteronyssinus represented the commonest sensitizing strains in studied samples in Egypt [7]. However, the published data on HDM sensitization from Egypt are scanty also; the association with severe asthma is not well known. The main purpose of this study was to determine the profile of some Egyptian asthmatic children who are sensitized to house dust mites and determine the association of HDM sensitization and severity of asthma according to recent GINA guidelines.

\section{Methods}

This is an observational, case control study. The study was carried out in Allergy, Clinical Immunology and pediatric pulmonology Unit, at Mansoura University Children Unit during the years 2018-2019. The study included 60 children above 6 years with atopic asthma. They were 42 males and 18 females; their age ranged from 8 to 17 years. Bronchial asthma diagnosis was based on clinical manifestations and spirometry results. Atopy was defined as presence of symptoms of atopic dermatitis, allergic rhino conjunctivitis, or food allergy; it was confirmed when asthmatic children fulfilled one of the following criteria: higher serum level of total $\operatorname{IgE}$ (more than $32 \mathrm{IU} / \mathrm{ml}$ ), eosinophilia (differential count more than $5 \%$ or absolute count more than $450 / \mu \mathrm{l}$ ), or positive skin prick test ( $3 \mathrm{~mm}$ greater than control).

Asthmatic children were maintained on controller therapy for at least 6 months. They were classified according to skin prick test results into two groups:

- Group1: It included 30 atopic asthmatic children, who were sensitive to one of the two HDM (D pteronyssinus or D farina).

- Group2: It included 30 atopic asthmatic children who were not sensitive to HDM allergy.

\section{Sampling}

Samples were convenient and patients were enrolled in the study by consecutive manner.

\section{Careful history taking}

- Personal and demographic data, e.g., age, sex, and residence.

- Asthma symptoms; cough, wheeze, as well as exercise-induced asthma.

- Symptoms of other atopic diseases in the child including allergic march.
- Based on frequency of each symptom, assessment of asthma control was done according to GINA 2017.

\section{Pulmonary function test (spirometry)}

Forced expiratory volume in $1 \mathrm{~s}$ (FEV1\%); forced vital capacity (FVC \%); FEV1/FVC ratio; and forced expiratory flow rate from 25 to $75 \%$ of vital capacity (FEF25-75\%) were measured by spirometry (Master Screen pediatrics). The highest reading of three successive measurements was taken. Reference values were computed according to the recommendations of the American Thoracic Society standards of acceptability and reproducibility in subjects above the age of 6 years who need cooperation for forced respiratory maneuver [8].

Skin prick test: for (Dermatophagoides pteronyssinus and Dermatophagoides farina). Through the use of specific allergen extracts, positive and negative controls, then interpretation after $15-20 \mathrm{~min}$ of maneuver, a wheal $\geq 3 \mathrm{~mm}$ diameter is considered positive [9]. Before the test, we checked that the patient has not taken medications that might interfere with the test and antihistamines had stopped using before the skin prick test (2 days for the first generation and 7 days for the second generation) [10].

\section{Eosinophil count}

Blood sample was collected in EDTA tube. Total leucocytic count and eosinophilia \% were determined by automated cell counter [11].

\section{Serum Ig $\mathrm{E}$}

Blood samples were collected into tubes with ethylene tetra-acetic acid (EDTA). After incubation at room temperature for $20 \mathrm{~min}$, tubes were centrifuged for $15 \mathrm{~min}$ at 2500 revolutions per minute (rpm). Supernatant levels of IgE were determined by the ELISA technique [12].

\section{Assessment level of asthma severity}

Classification of asthma according to disease severity is defined level (mild, moderate, severe) according to treatment steps when the patient has been maintained on regular controller therapy for several months. Patient maintained on step 2 treatments are often classified as having mild asthma. Those that receive steps $3-4$ as moderate asthma and those prescribed steps $4-5$ as having moderate to severe asthma [2].

\section{Assessment level of asthma control}

based on asthma control score according to GINA guideline defined as controlled, partially controlled and well controlled [3]. 


\section{Statistical analysis}

Data were fed to the computer and analyzed using IBM SPSS Corp. Released 2013. IBM SPSS Statistics for Windows, Version 22.0. Armonk, NY: IBM Corp. The following tests were used:

Qualitative data Chi-square test for comparison of 2 or more groups. Monte Carlo test as correction for Chisquare test when more than $25 \%$ of cells have count less than 5 in tables $(>2 \% 2)$.

Quantitative data between groups Student $t$ test was used to compare 2 independent group. Mann-Whitney $U$ test was used to compare 2 independent groups.

Spearman's correlation and binary stepwise logistic regression were used.

\section{Results}

- Table 1 shows mean age of the studied cases was 11.05 and 11.75 years respectively with $63.3 \%$ of cases sensitive to HDM and $76.7 \%$ of cases nonsensitive to HDM without statistically significant difference between both groups. The most frequent clinical phenotype among the HDMpositive group was a cough (96.7\%), while the clinical phenotypic wheeze was frequent in HDM negative group (96.7\%).

- There is a statistically significant difference between studied cases classified according to sensitivity to HDM regarding level of asthma control (50.0\% were uncontrolled among cases sensitive to HDM and $56.7 \%$ of cases non-sensitive to HDM were controlled $(p=0.001 *)$. Severity according to treatment results was significantly higher among cases sensitive to HDM (26.7\% of cases sensitive to HDM versus $3.3 \%$ of cases non-sensitive to HDM), $p=0.017^{*}$ (Table 1 ).

- There was a statistically significant association between atopic dermatitis frequency and sensitivity to HDM (43.3\% of cases sensitive to HDM and $70.0 \%$ among non-sensitive cases to HDM). A non-statistically significant difference was found between cases sensitive and nonsensitive to HDM regarding conjunctivitis, food allergy, rhinitis, IgE, and eosinophils median values (Table 2).

- Pulmonary function tests among cases according to sensitivity to house dust mites revealed that there was no statistically significant difference of mean $\mathrm{FEV} \%, \mathrm{FVC} \%$, and $\mathrm{FEV} / \mathrm{FVC} \%$ among cases sensitive to HDM than cases non-sensitive to HDM.

Table 1 Clinical and demographic characteristics among studied cases

\begin{tabular}{|c|c|c|c|}
\hline & \multicolumn{2}{|c|}{ Sensitivity to house dust mites. } & \multirow{2}{*}{$\begin{array}{l}\text { Test of } \\
\text { significance }\end{array}$} \\
\hline & $\begin{array}{l}\text { Positive } \\
N=30 \text { (\%) }\end{array}$ & $\begin{array}{l}\text { Negative } \\
N=30 \text { (\%) }\end{array}$ & \\
\hline \multicolumn{3}{|l|}{ Age/years } & \multirow{2}{*}{$\begin{array}{l}t=0.938 \\
p=0.352\end{array}$} \\
\hline mean $\pm S D$ & $11.05 \pm 2.74$ & $11.75 \pm 3.04$ & \\
\hline \multicolumn{4}{|l|}{ Sex } \\
\hline Male & $19(63.3)$ & $23(76.7)$ & $x^{2}=1.27$ \\
\hline Female & $11(36.7)$ & $7(23.3)$ & $p=0.260$ \\
\hline Difficulty of breathing & $25(83.3)$ & $27(93.1)$ & $\begin{array}{l}t=1.35 \\
p=0.246\end{array}$ \\
\hline Cough & $29(96.7)$ & $28(93.3)$ & $\begin{array}{l}\text { FET } \\
p=1.0\end{array}$ \\
\hline Wheezes & $27(90.0)$ & $29(96.7)$ & $\begin{array}{l}x^{2}=1.07 \\
p=0.301\end{array}$ \\
\hline \multicolumn{4}{|l|}{ Level of control } \\
\hline Uncontrolled & $15(50.0)$ & $8(26.7)$ & \multirow{3}{*}{$\begin{array}{l}M C \\
p=0.001^{*}\end{array}$} \\
\hline Controlled & $3(10.0)$ & $17(56.7)$ & \\
\hline Partially control & $12(40.0)$ & $5(16.6)$ & \\
\hline \multicolumn{4}{|c|}{ Severity according to treatment: } \\
\hline Mild & $8(26.7)$ & $16(53.3)$ & \multirow{3}{*}{$\begin{array}{l}\mathrm{MC} \\
p=0.017^{*}\end{array}$} \\
\hline Moderate & $14(46.6)$ & $13(43.3)$ & \\
\hline Severe & $8(26.7)$ & $1(3.4)$ & \\
\hline
\end{tabular}


Table 2 Allergic factors distribution among cases according to sensitivity to house dust mites

\begin{tabular}{|c|c|c|c|}
\hline \multirow[t]{2}{*}{ Allergy factors } & \multicolumn{2}{|c|}{ Sensitive to house dust mites. } & \multirow{2}{*}{$\begin{array}{l}\text { Test of } \\
\text { significance }\end{array}$} \\
\hline & $\begin{array}{l}\text { Positive } \\
N=30(\%)\end{array}$ & $\begin{array}{l}\text { Negative } \\
N=30(\%)\end{array}$ & \\
\hline Atopic dermatitis & $13(43.3)$ & $21(70.0)$ & $\begin{array}{l}x^{2}=4.34 \\
p=0.037^{*}\end{array}$ \\
\hline Allergic conjunctivitis & $18(60.0)$ & $20(66.70)$ & $\begin{array}{l}x^{2}=0.287 \\
p=0.592\end{array}$ \\
\hline Food allergy & $8(26.7)$ & $7(23.30$ & $\begin{array}{l}x^{2}=0.089 \\
p=0.766\end{array}$ \\
\hline Rhinitis & $26(86.7)$ & $22(73.3)$ & $\begin{array}{l}x^{2}=1.67 \\
p=0.197\end{array}$ \\
\hline \multicolumn{4}{|l|}{ Eosinophils \% } \\
\hline $\begin{array}{l}\text { Median (Range) } \\
\text { Mean } \pm \text { SD }\end{array}$ & $\begin{array}{l}4.07(0.16-15.7) \\
4.84 \pm 4.57\end{array}$ & $\begin{array}{l}2.95(0.22-4.84) \\
2.99 \pm 1.60\end{array}$ & $\begin{array}{l}z=0.549 \\
p=0.581\end{array}$ \\
\hline $\lg E I U / m l$ & & & \multirow{2}{*}{$\begin{array}{l}z=1.61 \\
p=0.107\end{array}$} \\
\hline Median (Range) & $159.70(2.6-2500)$ & $26.3(2.6-536)$ & \\
\hline
\end{tabular}

$x^{2}$ Chi-square test

*Statistically significant $(p<0.05)$

However, median MEF75\% was significantly lower among cases sensitive to HDM (46\% versus 55\%).

- Among significant predictors of moderate to severe bronchial asthma, sensitivity to HDM increases risk of severe asthma by 3.14 more times than non- sensitive cases $(\mathrm{OR}=3.14,95 \%$ CI 1.07-9.27), precipitation to smoke increases risk of asthma severity by 1.072 , and presence of dermatitis, conjunctivitis, and presence of food allergy increases risk of asthma severity by $(1.04,13.73$, and 1.06 , respectively) (Table 3, Fig. 1).

Table 3 Predictors of moderate and severe asthma among studied cases

\begin{tabular}{|c|c|c|c|}
\hline & B & $P$ & $\begin{array}{l}\text { AOR } \\
(95 \% \mathrm{Cl})\end{array}$ \\
\hline $\begin{array}{l}\text { Sensitivity to HDM } \\
+V E \\
-V E \text { (reference group) }\end{array}$ & 1.145 & $0.038^{*}$ & $\begin{array}{l}3.14(1.07-9.27) \\
1\end{array}$ \\
\hline Age/years & -0.015 & 0.878 & $0.985(0.817-1.189)$ \\
\hline MEF75\% & 0.012 & 0.539 & $1.012(0.975-1.05)$ \\
\hline FVC\% & .001 & 0.939 & $0.939(0.970-1.03)$ \\
\hline PEF & -0.018 & 0.326 & $0.982(0.947-1.018)$ \\
\hline Dyspnea & -1.227 & .414 & $.293(0.015-5.56)$ \\
\hline Cough & .211 & .915 & $1.235(0.026-59.65)$ \\
\hline Wheeze & -.495 & .804 & $.610(0.012-30.61)$ \\
\hline Infection & .225 & .824 & $1.253(0.171-9.17)$ \\
\hline Food & -1.090 & .208 & $.336(0.061-1.84)$ \\
\hline Emotion & -1.670 & .073 & $.188(0.03-1.17)$ \\
\hline Smoke & 2.625 & $.048^{*}$ & $1.072(1.005-1.972)$ \\
\hline Contact animals & 1.346 & .239 & $3.843(0.408-36.16)$ \\
\hline Allergy odor & .596 & .540 & $1.814(0.27-12.18)$ \\
\hline Dermatitis & 3.226 & $.006^{*}$ & $1.040(1.004-2.395)$ \\
\hline Conjunctivitis & 2.619 & $.031^{*}$ & $13.729(1.28-17.75)$ \\
\hline Food allergy & -2.805 & $.017^{*}$ & $1.061(1.006-2.603)$ \\
\hline Rhinitis & .257 & .809 & $1.29(0.161-10.41)$ \\
\hline
\end{tabular}




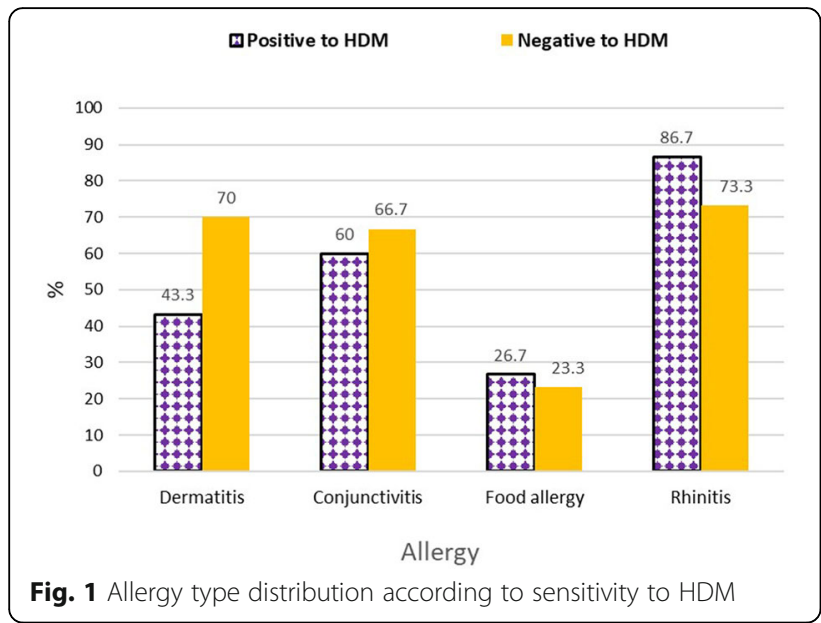

- Correlation between severity grade and pulmonary function tests among cases sensitive to HDM demonstrates a statistically significant negative correlation between asthma severity among cases sensitive to HDM and the following variables; MEF75 $(r=-0.412)$, level of asthma control $(r=-0.729), \mathrm{FEV} 1(r=-0.696), \mathrm{FEV} /$ FVC $(r=-0.613), \operatorname{PEF}(r=-0.564)$. In addition, there is a significant positive correlation between asthma severity and serum $\operatorname{IgE}(r=0.725)$. In addition, there was significant negative correlation between asthma severity and level of asthma control among those patients (Table 4).

- There is no statistically significant correlation between asthma severity among cases non-sensitive to HDM and age, pulmonary function tests, and laboratory results.

\section{Discussion}

HDM are considering the main indoor allergens to which infants and children are regularly exposed. In Egypt, prevalence of asthma among schoolchildren in Nile Delta region was previously assessed using modified ISAAC questionnaire and was found to be $7.7 \%$ [13]. Classification of asthma according to disease severity is defined by level (mild, moderate, severe) according to treatment steps after the patient has been maintained on controller asthma therapy for several months. As regards the comparison of clinical presentation between two groups, the present study found that the most frequent clinical phenotype among the HDM-positive group was cough (96.7\%), while clinical phenotypic wheeze was the most frequent among the HDM-negative group (96.7\%). Similar to our result, Wu et al. (2011) [14] who showed that among 286 children with cough variant asthma tested by skin prick test (SPT), the commonest allergen
Table 4 Correlation between severity grade in relation to pulmonary function tests and age, serum lgE, and asthma control among cases sensitive to HDM

\begin{tabular}{|c|c|c|}
\hline \multirow[b]{2}{*}{ Age/years } & \multicolumn{2}{|c|}{ Severity according to treatment } \\
\hline & Rs & .029 \\
\hline & $P$ & .878 \\
\hline \multirow[t]{2}{*}{$\lg E$} & Rs & .725 \\
\hline & $\mathrm{P}$ & $.027^{*}$ \\
\hline \multirow[t]{2}{*}{ Control level } & Rs & -.729 \\
\hline & $\mathrm{P}$ & $<0.001^{*}$ \\
\hline \multirow[t]{2}{*}{ FEV1\% } & Rs & -.696 \\
\hline & P & $<0.001^{*}$ \\
\hline \multirow[t]{2}{*}{ FVC\% } & Rs & .000 \\
\hline & $P$ & 1.000 \\
\hline \multirow[t]{2}{*}{ FEV/FVC\% } & Rs & -.613 \\
\hline & P & $<0.001^{*}$ \\
\hline \multirow[t]{2}{*}{ MEF75\% } & Rs & -.412 \\
\hline & $P$ & $.041^{*}$ \\
\hline \multirow[t]{2}{*}{ PEF } & Rs & -.564 \\
\hline & $P$ & $.002^{*}$ \\
\hline
\end{tabular}

rs Spearman correlation co-efficient

*Statistically significant (if $p<0.05$ )

were Dermatophagoides pteronyssinus and Dermatophagoides farinae $58.04 \%$ and $54.16 \%$ respectively.

In dissimilarity to that, Takemura et al. (2007) disclosed that patients with classic asthma phenotype whom presented with wheezing chest had higher rates of sensitization to HDM [15].

Regarding the co-existence of atopic dermatitis, the present study revealed that there is a statistically significant difference between HDM-positive groups (43.3\% versus $70 \%, p=0.037$ ) and HDM-negative groups.

Atopic dermatitis (AD) affects $15 \%$ to $30 \%$ of children [16]. In contrast to our result [17], Adham and Tawfik (2012) found that atopic patients with HDM hypersensitivity suffered more severe and more chronic forms atopic dermatitis. Also, Sybilski et al. (2015) showed that children with $\mathrm{AD}$ were sensitized most commonly to $D$. pteronyssinus and D. farinae allergens $\sim 30 \%$ of participants [18]. So further larger studies are needed to insure the relation between atopic dermatitis and to D. pteronyssinus and $D$. farinae allergens in our locality.

On the other hand, there was a higher frequency of allergic rhinitis in HDM-positive group (86.7\% versus 73.3 $\%, p=0.197)$ to HDM-negative group but without statistically significant difference in this study. In agreement with our result, the most common inhaled allergens to which the AR children were sensitive were Dermatophagoides pteronyssinus (69.3\%), Dermatophagoides farinae $(66.2 \%)$, and [19]. HDM allergens excreted in fecal 
pellets can be airborne and can easily enter the nostrils and airways so can contribute to allergic rhinitis or asthma pathogenesis [20].

This study showed that there was a higher level of median IgE level in positive HDM cases $159.7 \mathrm{IU} / \mathrm{ml}$ $(2.6-2500 \mathrm{IU} / \mathrm{ml})$ than HDM-negative cases $26.3 \mathrm{IU} /$ $\mathrm{ml}(2.6-536 \mathrm{IU} / \mathrm{ml})$, and there was weak statistically significant positive correlation between asthma severity and IgE level among positive cases in multivariate analysis ( $\mathrm{rs}=0.725, p=.027$ ). Similar to our result found by [21] and [22]. In contrast, Kumar et al. (2017) observed no significant correlation between serum IgE and the severity of asthma. According to the level of asthma control, there was a statistically significant difference between the two groups as regard numbers of the uncontrolled patients; (15 cases, $50 \%$ versus 8 cases, $26.7 \%, p=0.001$ ) between positive cases and negative cases [23].

In agreement with our study, Teo et al. (2015) showed that there was an association between sensitization to $D$. pteronyssinus and D. farinae and the control of asthma [24]. In contrast, Tanaka et al. (2016) showed that sensitization to house dust mites, Japanese cedar was not associated with poor asthma control [25]; this can be explained by different environmental factors including climate and degree of humidity in different localities.

In this study as regard asthma severity, cases were divided into mild, moderate, and severe according to treatment steps. There was a statistically significant difference between the two groups as regard to severe cases $(26.7 \%$ of positive group versus $3.3 \%$ negative group; $p=0.017$ ).

In harmony with our result, Jiménez-Feijoo et al. (2019) explained that sensitization to Der p allergen must be considered in the diagnosing and treating mite allergy, particularly in cases with moderate and severe asthma as it might worsen the clinical phenotype [26]. In contrast to this, Just et al. (2017) showed that in allergic asthma phenotype, ninety-eight percent of children in HDM-sensitized group had mild asthma [27]. As regard PFTS, there is statistically significant difference in mean values of MEV 75\% ( $p=0.031)$ between two groups, while there is no statistically significant difference in mean values of FEV, FEV/FVC\% $(p=0.127$ and $p=0.197$ respectively) between two groups. There was no statistically significant difference between two groups as regard severity of disease according to FEV1. In the current work, there was statistically significant negative correlation between severity, PFTS values FEV1, and FEV/FVC\% (both $p$ value $>0.00$ ) among cases sensitive to HDM.

Reduced FEV1\% is commonly used to define the degree of asthma severity in children treatment guideline. In addition, Mingotti et al. (2020) showed that $\mathrm{FEV}_{1} /$
FVC\% in the lower range of normality is a marker of worse clinical outcomes in asthmatics without airway obstruction [28].

Contrary to adult and our result, spirometry usually have less predictive value in assessment of asthma severity in young children, also previous studies examining the relation between FEV1\% and asthma severity in children revealed a very weak correlation between pulmonary function and asthma symptoms [29].

We believe that a limitation of our result is due to the relatively small sample size studied; therefore, further studies on larger number of Egyptian asthmatic children may achieve significant findings.

\section{Conclusions}

HDM sensitization is associated mainly with cough asthma phenotype and allergic rhinitis in our studied cases. HDM sensitization increases asthma severity and decreases the ability to control asthma symptoms. So our recommendations include:

- Skin testing should be considered for all asthmatic patients with uncontrolled asthma.

- Early diagnosis and stop of exposure to allergens are essential to prevent further deterioration of lung function.

- Measures to avoid HDM should be considered in asthmatic patient's homes including occlusive airpermeable fabric protectors that prevent the HDM from getting through the bedding for pillows and mattresses in addition to use of hardwood floors.

- Immunotherapy can be used to combat HDM consequences of allergy.

- Severe asthma categorization into phenotypes and endotypes, using specific biomarkers, led to the concepts of "personalized medicine." Therefore, the use of anti-IgE monoclonal antibody will be beneficial in patients with higher level of total IgE level. Also, follow up of serum IgE can be used to follow severity improvement instead of repeating skin test.

\section{Abbreviations}

Der F: Dermatophagoides farina; Der P: Dermatophagoides pteronyssinus; FEV1: Forced expiratory volume in 1 second; FVC: Forced vital capacity; FEF25-75: Forced expiratory flow rate from 25 to $75 \%$ of vital capacity; GINA: Global initiative for asthma; HDM: House dust mite; IgE: Immunoglobulin E; SPT: Skin prick test; PFTS: Pulmonary function tests

\section{Acknowledgements}

Not applicable.

\section{Authors' contributions}

SA designed research study and revised the paper. O E analyzed and interpreted the patient data regarding pulmonary function and skin testing and was a major contributor in writing the manuscript. ON collected data. All authors read and approved the final manuscript. 


\section{Funding}

There is no funding.

\section{Availability of data and materials}

All data and material are available.

\section{Declarations}

\section{Ethics approval and consent to participate}

The protocol was approved by Ethical Committee of Faculty of Medicine, Mansoura University at 31/7/2018, the code number (Ms.18.07.201.) confidentially and personal privacy have been respected. An informed verbal consent was obtained from caregivers of all patients and approved by Ethical Committee of Faculty of Medicine.ClinicalTrials.gov Identifier: NCT04958616.

\section{Consent for publication}

Not applicable.

\section{Competing interests}

The authors declare that they have no competing interests.

\section{Author details}

'Pediatric Department, Mansoura University Faculty of Medicine, Mansoura, Egypt. ${ }^{2}$ Nephrology Unit, Mansoura University Faculty of Medicine, Mansoura, Egypt. ${ }^{3}$ Allergy and Pediatric Pulmonology Unit, Mansoura University Faculty of Medicine, Mansoura, Egypt.

Received: 15 April 2021 Accepted: 23 July 2021

Published online: 28 August 2021

\section{References}

1. Global Initiative for Asthma. Global strategy for asthma management and prevention, 2020. Available from: http://www.ginasthma.

2. Global Initiative for Asthma. Global strategy for asthma management and prevention, 2017. Available from: http://www.ginasthma.

3. Alith MB, Gazzotti MR, Nascimento OA, Jardim JR (2020) Impact of asthma control on different age groups in five Latin American countries. World Allergy Organ J 13(4):100113. Published 2020 Apr 1. https://doi.org/10.1016/ j.waojou.2020.100113

4. Yang L, Zhu R (2017) Immunotherapy of house dust mite allergy. Hum Vaccin Immunother 13(10):2390-2396. https://doi.org/10.1080/21645515.2017.1364823

5. Dey D, Saha GK, Podder S (2019) A review of house dust mite allergy in India. Exp Appl Acarol 78(1):1-14. https://doi.org/10.1007/s10493-019-00366-4

6. Wilson JM, Platts-Mills TAE (2018) Home environmental interventions for house dust mite. J Allergy Clin Immunol Pract 6(1):1-7. https://doi.org/10.1 016/j.jaip.2017.10.003

7. Hossny E, El-Sayed S, Abdul-Rahman N (2014) Sensitivity to five types of house dust mite in a group of allergic egyptian children. Pediatr Allergy Immunol Pulmonol 27(3):133-137. https://doi.org/10.1089/ped.2014.0333

8. Hankinson JL, Bang KM (1991) Acceptability and reproducibility criteria of the American Thoracic Society as observed in a sample of the general population. Am Rev Respir Dis 143(3):516-521. https://doi.org/10.1164/a jrccm/143.3.516

9. Heinzerling L, Mari A, Bergmann KC, Bresciani M, Burbach G, Darsow U, Durham S, Fokkens W, Gjomarkaj M, Haahtela T, Bom AT, Wöhrl S, Maibach H, Lockey R (2013) The skin prick test-European standards. Clin Transl Allergy 3(1):3. https://doi.org/10.1186/2045-7022-3-3

10. Ansotegui IJ, Melioli G, Canonica GW, Caraballo L, Villa E, Ebisawa M, Passalacqua G, Savi E, Ebo D, Gómez RM, Luengo Sánchez O, Oppenheimer JJ, Jensen-Jarolim E, Fischer DA, Haahtela T, Antila M, Bousquet JJ, Cardona V, Chiang WC, Demoly PM, DuBuske LM, Ferrer Puga M, Gerth van Wijk R, González Díaz SN, Gonzalez-Estrada A, Jares E, Kalpaklioğlu AF, Kase Tanno L, Kowalski ML, Ledford DK, Monge Ortega OP, Morais Almeida M, Pfaar O, Poulsen LK, Pawankar R, Renz HE, Romano AG, Rosário Filho NA, Rosenwasser L, Sánchez Borges MA, Scala E, Senna GE, Sisul JC, Tang MLK, Thong BYH, Valenta R, Wood RA, Zuberbier T (2020) IgE allergy diagnostics and other relevant tests in allergy, a World Allergy Organization position paper. World Allergy Organ J 13(2):100080. https://doi.org/10.1016/j.wa ojou.2019.100080
11. Orkin SH, Nathan DG, Ginsburg D, Look AT, Fisher DE, Lux S (2008) Nathan and Oski's hematology of infancy and childhood E-Book. Elsevier Health Sciences

12. Mukai K, Tsai M, Starkl P, Marichal T, Galli SJ (2016) lgE and mast cells in host defense against parasites and venoms. Semin Immunopathol 38(5): 581-603. https://doi.org/10.1007/s00281-016-0565-1

13. Zedan M, Settin A, Farag M, Ezz-Elregal M, Osman E, Fouda A (2009) Prevalence of bronchial asthma among Egyptian school children. Egypt J Bronchol 3(2):124-130

14. Wu Y, Ai T, Luo RH (2011) An analysis of skin prink test in children with cough variant asthma in Chengdu areas. Sichuan Med J 32:310-312 PMID: 12449666

15. Takemura M, Niimi A, Matsumoto H, Ueda T, Yamaguchi M, Matsuoka H, Jinnai M, Chin K, Mishima M (2007) Atopic features of cough variant asthma and classic asthma with wheezing. Clin Exp Allergy 37(12):1833-1839. https://doi.org/10.1111/j.1365-2222.2007.02848.x

16. Flohr C, Mann J (2014) New insights into the epidemiology of childhood atopic dermatitis. Allergy. 69(1):3-16. https://doi.org/10.1111/all.12270

17. Adham TM, Tawfik SA (2012) Dermatophagoides in childhood asthma. Saudi Med J 33(3):292-297

18. Sybilski AJ, Zalewska M, Furmańczyk K, Lipiec A, Krzych-Fałta E, Samoliński B (2015) The prevalence of sensitization to inhalant allergens in children with atopic dermatitis. Allergy Asthma Proc 36(5):e81-e85. https://doi.org/10.2 500/aap.2015.36.3882

19. Lin $H$, Lin R, Li N (2015) Sensitization rates for various allergens in children with allergic rhinitis in Qingdao, China. Int J Environ Res Public Health 12(9): 10984-10994. https://doi.org/10.3390/ijerph120910984

20. Park KH, Lee J, Lee JY, Lee SC, Sim DW, Shin JU, Park CO, Lee JH, Lee KH, Jeong KY, Park JW (2018) Sensitization to various minor house dust mite allergens is greater in patients with atopic dermatitis than in those with respiratory allergic disease. Clin Exp Allergy 48(8):1050-1058. https://doi. org/10.1111/cea.13164

21. Haktanir Abul M, Phipatanakul W (2019) Severe asthma in children: evaluation and management. Allergol Int 68(2):150-157. https://doi.org/10.1 016/.alit.2018.11.007

22. Sacco O, Sale R, Silvestri M, Serpero L, Sabatini F, Raynal ME, Biraghi M, Rossi GA (2003) Total and allergen-specific lgE levels in serum reflect blood eosinophilia and fractional exhaled nitric oxide concentrations but not pulmonary functions in allergic asthmatic children sensitized to house dust mites. Pediatr Allergy Immunol 14(6):475-481. https://doi.org/10.1046/j.09056157.2003.00092.x

23. Kumar RM, Pajanivel R, Koteeswaran G, Menon SK, Charles PM (2017) Correlation of total serum immunoglobulin E level, sputum, and peripheral eosinophil count in assessing the clinical severity in bronchial asthma. Lung India 34(3):256-261. https://doi.org/10.4103/lungindia.lungindia

24. Teo KS, Cheah CW, Mak JW (2015) Association between house dust mite (HDM) sensitisation and asthma control using skin prick test and HDM antigen specific lgE levels in saliva of Malaysian children. Int eJ Sci Med Educ 9:3e12

25. Tanaka A, Fujiwara A, Uchida Y, Yamaguchi M, Ohta S, Homma T et al (2016) Evaluation of the association between sensitization to common inhalant fungi and poor asthma control. Ann Allergy Asthma Immunol 117(2):163-168.e1. https://doi.org/10.1016/j.anai.2016.06.001

26. Jiménez-Feijoo R, Pascal M, Moya R, Riggioni C, Domínguez O, Lózano J, Álvaro-Lozano M, Piquert M, Machinena A, Folque M, Dias M, Carnés J, Plaza AM (2020) Molecular diagnosis in house dust mite-allergic patients suggests that Der p 23 is clinically relevant in asthmatic children. J Investig Allergol Clin Immunol 30(2):127-132. https://doi.org/10.18176/jiaci.0431

27. Just J, Bourgoin-Heck M, Amat F (2017) Clinical phenotypes in asthma during childhood. Clin Exp Allergy 47(7):848-855. https:/doi.org/10.1111/cea.12939

28. Mingotti C, Sarinho J, Stanigher K, Silva J, Roquette E, Marchi E, Ponte EV (2020) Evaluating the FEV1/FVC ratio in the lower range of normality as a marker of worse clinical outcomes in asthmatic subjects without airway obstruction. Respir Med 162:105880. https://doi.org/10.1016/j.rmed.2020.105880

29. Schifano ED, Hollenbach JP, Cloutier MM (2014) Mismatch between asthma symptoms and spirometry: implications for managing asthma in children. J Pediatr 165(5):997-1002. https://doi.org/10.1016/j.jpeds.2014.07.026

\section{Publisher's Note}

Springer Nature remains neutral with regard to jurisdictional claims in published maps and institutional affiliations. 